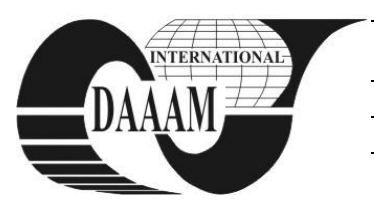

Annals of DAAAM for 2012 \& Proceedings of the 23rd International DAAAM Symposium, Volume 23, No.1, ISSN 2304-1382 ISBN 978-3-901509-91-9, CDROM version, Ed. B. Katalinic, Published by DAAAM International, Vienna, Austria, EU, 2012 Make Harmony between Technology and Nature, and Your Mind will Fly Free as a Bird

Annals \& Proceedings of DAAAM International 2012

\title{
COLLABORATION AND NEW PRODUCT DEVELOPMENT IN PLM ENVIRONMENT
}

\author{
ORCIK, A[nja]; ANISIC, Z[oran] \& COSIC, I[lija]
}

\begin{abstract}
In contemporary business environment, companies realize the importance of collaboration throughout the entire product lifecycle. The focus of the paper is on the collaboration in New Product Development (NPD) processes and how Product Lifecycle Management (PLM) strategy can support advanced collaboration strategies, such as Mass Customization and Customer Co-Creation. The connection between these strategies and product lifecycle phases related to New Product Development is made. This paper represents the basis for the further research that is going to be taken in order to develop the first author's PhD thesis.

Keywords: Collaboration, Customer Co-Creation, Mass Customization, New Product Development, Product Lifecycle Management
\end{abstract}

\section{INTRODUCTION}

In contemporary dynamic business environment there is a shift in how product value is perceived and created. Companies are realizing the importance of collaboration for creating and sustaining competitive advantage [1]. The traditional company-centric view is being replaced by the customer-centric view, creating a market environment in which companies and consumers cocreate experiences [2].

The trend to individualization with its social and economical dimensions is a precondition for the development of advanced collaboration strategies. Mass Customization and Personalization becomes a common practice in collaborating with customers in New Product Development (NPD), where product designers' responsibility shifts from designing a product to designing components which are then configurable by the customer, the ultimate designer [3]. Customer CoCreation represents a step further. Prahalad and Ramaswamy (2004) suggest that the future of competition will be based on a new approach to value creation, where consumers want to interact with whole communities of professional service providers and other consumers, in order to co-create value [2]. Efficient NPD is hard to imagine out of Product Lifecycle Management (PLM) strategy and contemporary software solutions [4]. PLM is recognized as one of the most effective approaches for better, fast and cheaper product development and management.

The purpose of this paper is to identify key characteristics of collaboration in NPD by synthesizing principal contributions to this emerging field. After a general discussion about collaboration and NPD, the paper examines PLM as the collaborative environment and its role in supporting advanced collaboration strategies, such as Mass Customization and Customer Co-Creation. The research approach taken in this part relies on theoretical assumptions and some practical examples. The paper ends with some conclusions and propositions for further research. The first author's $\mathrm{PhD}$ thesis should develop and extend some of ideas presented here into a more general and detailed way.

\section{COLLABORATION AND NEW PRODUCT DEVELOPMENT}

Collaboration with partners, customers and competitors has become a strategic imperative for companies in the networked world of business. Collaboration with customers can span several business processes, with the focus on collaborating to create value through NPD. Prahalad and Ramaswamy (2004) have made the distinction between company-centric and customer-centric view. Companies have always tried to "hear the voice of the customer". However, customers have traditionally played a passive role in NPD processes. In this traditional company-centric view: (1) the consumer is outside the domain of the value chain; (2) the enterprise controls where, when, and how value is added in the value chain; (3) value is created in a series of activities controlled by the enterprise before the point of purchase; (4) there is a single point of exchange where value is extracted from the customer for the enterprise [2]. When customers are viewed as passive recipients of innovation, the company has a limited understanding of customer knowledge developed within their specific contexts of experience [1]. Collaboration enables the customer-centric view, where: (1) the consumer is an integral part of the system for value creation; (2) the consumer can influence where, when, and how value is generated; (3) the consumer need not respect industry boundaries in the search for value; (4) the consumer can compete with companies for value extraction; (5) there are multiple points of exchange where the consumer and the company can co-create value [2].

Since new products very often fail to match customer needs, improving interaction with customers during NPD process is an important challenge in order to reduce failure rates and to increase financial returns from high investments. In this regard, customer co-creation in NPD process is an emergent domain [5]. Company is the one that decides how much it can involve the customers into the NPD processes. Over the years, the degree of 
customers' involvement is getting higher - from the customer left outside the creation of product value to codevelopment teams, Mass Customization and, most recently, Customer Co-Creation.

Mass Customization alters the traditional product development and moves towards a two-stage model. The first stage is the realm of company/designer establishing the solution space and the second, that of customer as codesigner [6]. According to Reichwald et al. (2004), this second stage fundamentally changes the role of the customer from consumer of a product, to a partner in a process of adding value [7]. In this way, Mass Customization enables companies to offer variety to customers and creates their emotional connection with the product. However, companies still decide what can be customized. Customization ultimately is a matter of what can be built and delivered to suit the efficient operation of a company's value chain. Even in the most sophisticated Mass Customization schemes, the customer chooses from a menu dictated by the company [2].

According to Prahalad and Ramaswamy (2004), in the twenty-first-century economy the focus should be centered on co-creation of unique value with customers. The customers' role in the industrial system has changed from isolated to connected, from unaware to informed, from passive to active, and their great influence in value creation is supported by information access, global view, networking, experimentation and activism [2]. Piller et al. (2012) defined Customer Co-Creation as an active, creative and social collaboration process between producers and customers (users), facilitated by a company, in the context of new product or service development [8]. The information and communications technology, the Internet in particular, is forcing companies to think differently about value creation and to be more responsive to consumer experiences [2]. Customer Co-Creation should not be confused with the transfer or outsourcing of activities to customers, or the marginal customization of goods and services. Rather co-creation is a value creation process in which suppliers and customers engage in interactions to exchange knowledge and resources in order to co-create value [9].

\section{PRODUCT LIFECYCLE MANAGEMENT AS THE COLLABORATIVE ENVIRONMENT}

Collaboration at the highest level could be viewed as a framework to connect people, processes and data (Information). This integration cannot happen without the underlying PLM framework since people, process and data is all centered on a product and the product lifecycle management involves interaction between people, process and information [10].

According to Danesi et al. [11], the catchword of PLM is collaborative work within product design processes in order to integrate all the partners and all associated knowledge efficiently. PLM provides customers, developers, manufacturers, and suppliers with the most effective means by collaboratively managing business activities throughout entire product lifecycle. PLM supports the capability of collaborative creation, management, dissemination and use of product assets (including data information and knowledge) in virtual enterprise integrating people, processes, and technology [12]. PLM is a concept based on horizontal business processes as compared to vertical business units in organization. These business units are linked based on product life stages and processes. Implementing a scalable and successful PLM strategy requires re-alignment or re-structuring of internal or external organizational structures [10].

The vision of PLM is to provide outstanding R\&D performance. This is achieved through the three drivers of PLM, namely management efficiency, process excellence and technology effectiveness [13]. In today's global business environment, that includes all the aspects of the product and its surroundings, product development is highly dependent on knowledge intensive and collaborative systems for building on specialized knowledge across nations, organizations, and professions to develop customized products for different market segments [6]. A knowledge support system, such as PLM, can provide a solution to support NPD processes by sharing and reusing knowledge related to these processes. PLM provides cooperative work systems that enable real-time collaboration (collaborative product development, web conferencing, simultaneous modifications with desktop sharing) and virtual product visualization (3D presentation viewer, different representations or views of product information) [14].

Virtual environments increase the speed and the persistence of customer engagement, because customers interactions can happen in real-time, and with a much higher efficiency [1]. Customers have the important role in each stage of the product lifecycle, from concept generation to phase-out and disposal.

However, at this point appears the question - How early the customers get integrated into the product lifecycle? The degree of product customization and personalization depends on the answer to this question. The earlier the customers get involved into the NPD, the higher is the degree of customization and personalization. If they get integrated in the earliest stages of NPD, the product customization moves towards personalized experience value and knowledge co-creation.

The framework of eight different styles of firmcustomer knowledge co-creation, represented by the OMC Group (2006), is shown on the Figure 1. This framework is built upon two criteria: (1) the degree of the personalization of the value created, and (2) the point where value creation occurs. According to this framework, Mass Customization is defined as a concept that provides the customer with a limited set of companydetermined choices or options with which the customers can personalize a standard product or service template. On the other hand, Personalized Experience Value and Knowledge Co-Creation are defined as a concept where the company and customers interact within an experience environment to realize unique co-created value [15]. Comparing to Mass Customization, in Co-Creation customers get involved in the earlier stages of the product lifecycle. 


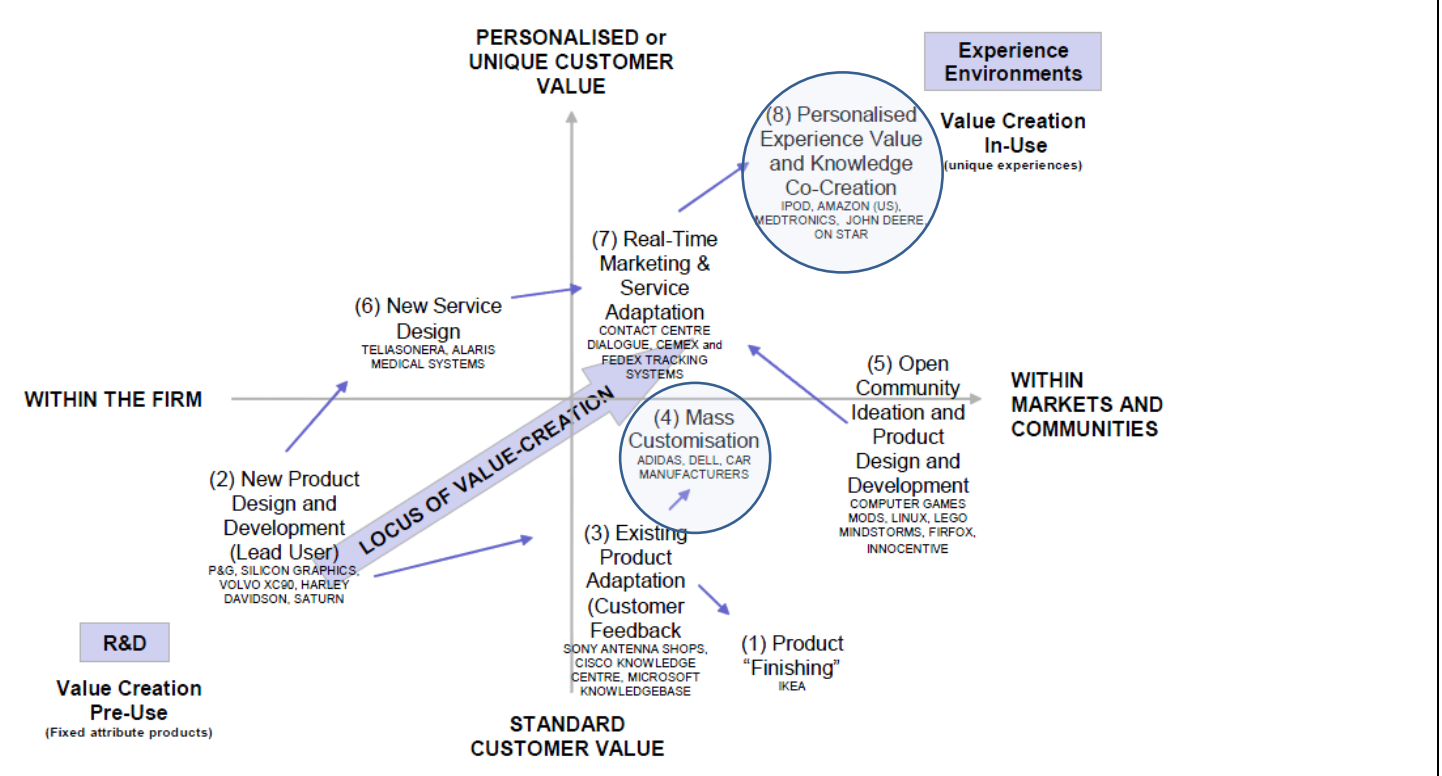

Fig. 1. The position of Mass Customization and Co-Creation in the framework of eight styles of firm-customer knowledge co-creation [15]

The objective of collaboration is to answer better the questions of time to market, cost and quality criterion [11], which can be accomplished with the support of PLM. As a business strategy, PLM enables companies to capture best business practices and store valuable intellectual capital for systematic and repeatable re-use. This is supported by PLM information systems that generate coherent data structures that enable real-time collaboration and data sharing. These characteristics of PLM systems are crucial in supporting advanced collaboration strategies, such as Mass Customization and Customer Co-Creation. PLM facilitates these collaboration strategies by enabling to rapidly and costs effectively deliver customized and co-created product offerings that satisfy the needs of individual customers and targeted market segments.

\subsection{Mass Customization in PLM environment}

Different Mass Customization strategies need different information systems to support them, and the integration of these information systems within the entire supply chain plays an essential role in the successful implementation of Mass Customization [16]. Frutos and Borenstein (2004) list necessary functionalities for such an information system as [17]: (1) facilitation of collaborative product development; (2) eliciting knowledge about clients; (3) virtual enterprise environment; (4) providing enrichments to clients; and (5) providing open system architecture. PLM systems provide these functionalities. In addition, they have the ability to support Mass Customization [18], by capturing Voice of the Customer $(\mathrm{VoC})$, translating it into integrated product requirements and efficiently managing those requirements, as well as, by combining the advantages of configuration management with option and variant management [19]. Supported by PLM solutions, product configurators are used to translate customer needs into product designs in order to deliver a final solution based on product realization knowledge [20] and they represent the design tools that are responsible for guiding the user through the configuration process [21].

\subsection{Customer Co-Creation in PLM environment}

As it is said earlier, Co-Creation involves giving customers the right to participate in the design of their own experience, not only by giving input about what they like and do not like as in traditional market research, but also by giving them tools that allow them to become actual designers [22].

On October 24, 2011, Siemens PLM Software announced a partnership with Local Motors, an American car company employing a distinctive, collaborative approach to vehicle design, that leverages a global, open, design community that contributes to the definition and design of an automobile [23]. This company's CoCreation strategy is supported by 3D Viewer and Solid Edge Design1, Siemens PLM Software solutions. The Co-Creation model (Figure 2) as envisioned by Local Motors is much deeper than simply configuring a product after it has been developed [24]. Local Motors allows any interested individual to join its design community. They can develop new cars and develop concepts, and on their way to get the car they want, they get tools, buildertrainer, all the help needed and shared experience, that is the key of the co-creation.

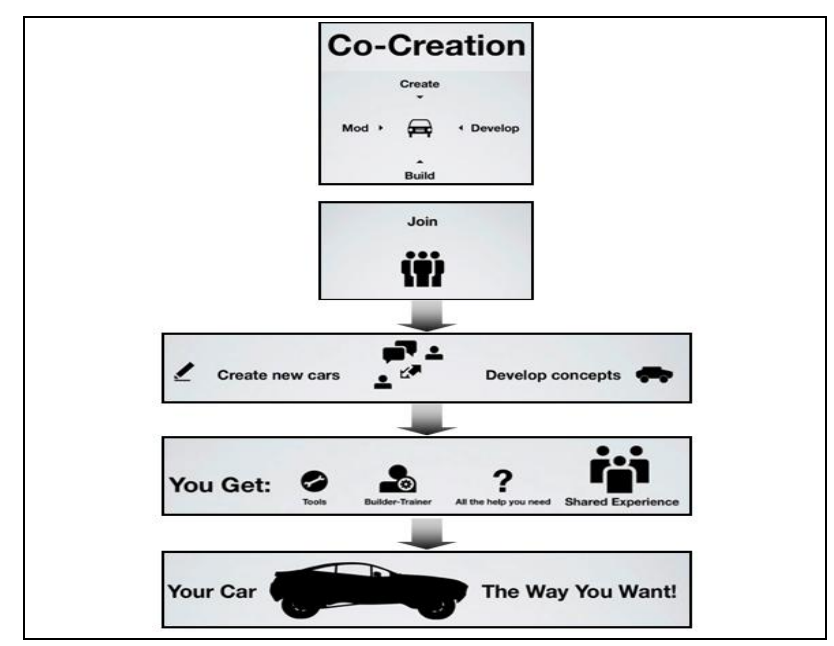

Fig. 2. Local Motors Co-Creation Model 
The five "Co-s" model, developed by Russo-Spena and Mele (2012), can be recognized in Local Motors CoCreation model. The five "Co-s" model includes five phases of Co-Creation: co-ideation, co-valuation, co-design, co-test and co-launch. The "Co-s" for innovation can be seen as different phases of the innovation processes in which actors interact, collaborate and integrate their resources [25].

According to John Fox, the Vice President of Siemens PLM Software, PLM solution "really help Local Motors provide their customers with what they are asking for better tools for design and collaboration. Their customers will be more productive, and the experience on the Local Motors platform will be more interactive and fun" [24]. Local Motors has proven that entire vehicles and components can be designed, engineered and built with successful results through Co-Creation. Local Motors hosts over 13,000 community contributors and growing, including customers as well as amateur to professional designers, engineers and fabricators [26].

\section{CONCLUSION}

Apart from competitive products, flexibility, fast innovation and knowledge application, companies also need IT strategies that incorporate principles of value creation and systems more sensitive to the customers' perception of value. Collaborative virtual environments enable capturing and managing customer knowledge and experience. Mass Customization and Customer CoCreation are the most influencing collaborative strategies nowadays, considering that Co-Creation provides customer's involvement earlier in the product lifecycle phases related to product development, assuring higher product value for them.

There is some research on Service Lifecycle Management (SLCM) that could involve the service community, on-going service evaluation and co-creation of revised service offerings [27]. SLCM and PLM can be taken as the basis for further research, that will encompass the parallel development of models of both product and service co-creation, emphasizing the similarities and differences between them. Series of casestudies on collaborative strategies and their relation with PLM and SLCM need to be taken. This will help to prove if PLM environment is able to support Mass Customization and Customer Co-Creation. However, this research will be limited by the fact that PLM approach is rarely implemented in Serbian enterprises, so it will have to be driven in the broader region. This means that differences in culture, as the important influencing factor, will have to be considered in this future research.

\section{REFERENCES}

[1] Sawhey, M., Verona, G., \& Prandelli, E. (2005). Collaborating to create: The Internet as a platform for customer engagement in product innovation. Journal of Interactive Marketing, 19 (4), 4-17.

[2] Prahalad, C. K., \& Ramaswamy, V. (2004). Co-creating unique value with customers. Strategy \& Leadership, 32 (3), 4-9.

[3] Grubb, D. (2006). Mass Customization — if you aren't doing it, maybe you should be. Wood Digest, 38-39.

[4] Orcik, A., Anisic, Z., Gecevska, V., \& Veza, I. (2012). Implementation of PLM strategy in the process of the new product development in chemical industry. International Conference - Management of Technology and Sustainable Production. Zadar, Croatia.
[5] Altun, K., Dereli, T., \& Baykasoglu, A. (2012). Development of a framework for customer co-creation in NPD through multi-issue negotiation with issue trade-offs. Expert Systems with Applications.

[6] Furstner, I., Anisic, Z., \& Cosic, I. (2008). Overview of Current Research Results of Mass Customization. 3rd International Conference on Mass Customization and Personalization in Central Europe, (pp. 65-73). Palic, Serbia.

[7] Reichwald, R., Seifert, S., Walcher, D., \& Piller, F. (2004). Customers as part of value webs: Towards a framework for webbed customer innovation tools. Proceedings of the 37th Annual Hawaii International Conference on System Sciences. Hawaii.

[8] Piller, F., Vossen, C., \& Ihl, C. From Social Media to Social Product Development: The impact of Social Media on Co-Creation of Innovation. Die Unternehmung, 66 (1), 7-27.

[9] Moller, K., Svahn, S., \& Finland, H. (2006). Role of knowledge in value creation in business nets. Journal of Management Studies, 43 (5), 985-1007.

[10] Sharma, A. (2005). Collaborative product innovation: integrating elements of CPI via PLM framework. Computer-Aided Design, 37, 1425-1434.

[11] Danesi, F., Gardan, N., Gardan, Y., \& Reimeringer, M. (2008). P4LM: A methodology for product lifecycle management. Computers in Industry, 59, 304-317.

[12] Gecevska, V., Anisic, Z., \& Chiabert, P. (2010). Solutions of Collaborative Product Lifecycle Management. 4th International Conference on Mass Customization and Personalization in Central Europe, (pp. 65-71). Novi Sad, Serbia.

[13]Ebert, C., \& Man, J. D. (2008). Effectively utilizing project, product and process knowledge. Information and Software Technology, 50, 579-594.

[14] Merminod, V., \& Rowe, F. (2012). How does PLM technology support knowledge transfer and translation in new product development? Transparency and boundary spanners in an international context. Information and Organization, 22, 295-322.

[15]Lawer, C. (2006). Eight Styles of Firm-Customer Knowledge CoCreation. OMC Group Insight.

[16] Ruohonen, M., Riihimaa, J., \& Makipaa, M. (2006). Knowledge based mass customization strategies: cases from Finnish metal and electronics industries. International Journal of Mass Customization, 1 (2-3), 340-359.

[17]Frutos, J., \& Borenstein, D. (2004). A framework to support customer company interaction in mass customization environments. Computers in Industry, 54 (2), 115-35.

[18] Orcik, A., Stojanova, T., Suzic, N., \& Gecevska, V. (2012). Requirements Management as a PLM Tool in Supporting Mass Customization. Proceedings of 5th International Conference on Mass Customization and Personalization in Central Europe, (pp. 175-179). Novi Sad, Serbia.

[19] Siemens PLM Software. (n.d.). Product lifecycle management from concept ideation to retirement, PLM software to build the right product - and build the product right. Retrieved September 10, 2012, from Siemens PLM Software: www.siemens.com/plm

[20] Chen, Z., \& Wang, I. (2010). Personalized product configuration rules with dual formulations: a method to proactively leverage mass confusion. Expert Systems with Applications, 37 (1), 383-392.

[21] Gjeldum, N., Veza, I., \& Beram, Z. (2012). Design Tool for Solar Panels Product Customization. Proceedings of 5th International Conference on Mass Customization and Personalization in Central Europe, (pp. 82-87). Novi Sad, Serbia.

[22] Gouillart, F. (2011, March 9). Engagement Platforms Must Enable Cocreation. Retrieved September 10, 2012, from HBR: http://blogs.hbr.org/cs/2011/03/engagement_platforms_must.html

[23] CIM Data. (2012). Siemens PLM Software Leverages Crowd Sourcing to Promote Solid Edge and JT. Retrieved September 10, 2012, from CIMData: http://www.cimdata.com/publications/commentary.html?commentary_ID=75

[24] Younomy. (2012). John Fox, Siemens PLM Software, Guru Speak. Retrieved September 10, 2012, from Making Business Social Younomy: http://www.younomy.com/guruspeak-john-foxsiemens-plmsoftware.html

[25] Russo-Spena, T., \& Mele, C. (2012). "Five Co-s" in innovating: a practice-based view. Journal of Service Management, 23 (4), 527-553.

[26] Local Motors Launches "The Forge," its Virtual Co-Creation Platform for the Auto Industry. (2011, December 1). Retrieved September 10, 2012, from Muscle Cars of America: http://www.musclecarsofamerica.com/permalink.php?id=664

[27] Lusch, R. F., Vargo, S. L., \& Tanniru, M. (2010). Service, value networks and learning. Journal of the Academy of Marketing Science, 38, 19-31 